\title{
Improving ozone profile retrieval from spaceborne UV backscatter spectrometers using convergence behaviour diagnostics
}

\author{
B. Mijling, O. N. E. Tuinder, R. F. van Oss, and R. J. van der A \\ Royal Netherlands Meteorological Institute (KNMI), Postbus 201, 3730-AE De Bilt, The Netherlands \\ Received: 12 February 2010 - Published in Atmos. Meas. Tech. Discuss.: 25 March 2010 \\ Revised: 4 November 2010 - Accepted: 5 November 2010 - Published: 12 November 2010
}

\begin{abstract}
The Ozone Profile Algorithm (OPERA), developed at KNMI, retrieves the vertical ozone distribution from nadir spectral satellite measurements of back scattered sunlight in the ultraviolet and visible wavelength range. To produce consistent global datasets the algorithm needs to have good global performance, while short computation time facilitates the use of the algorithm in near real time applications.
\end{abstract}

To test the global performance of the algorithm we look at the convergence behaviour as diagnostic tool of the ozone profile retrievals from the GOME instrument (on board ERS2) for February and October 1998. In this way, we uncover different classes of retrieval problems, related to the South Atlantic Anomaly, low cloud fractions over deserts, desert dust outflow over the ocean, and the intertropical convergence zone. The influence of the first guess and the external input data including the ozone cross-sections and the ozone climatologies on the retrieval performance is also investigated. By using a priori ozone profiles which are selected on the expected total ozone column, retrieval problems due to anomalous ozone distributions (such as in the ozone hole) can be avoided.

By applying the algorithm adaptations the convergence statistics improve considerably, not only increasing the number of successful retrievals, but also reducing the average computation time, due to less iteration steps per retrieval. For February 1998, non-convergence was brought down from $10.7 \%$ to $2.1 \%$, while the mean number of iteration steps (which dominates the computational time) dropped 26\% from 5.11 to 3.79 .

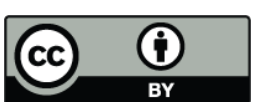

Correspondence to: B. Mijling (mijling@knmi.nl)

\section{Introduction}

There is a great need for information on the state and evolution of the global three-dimensional distribution of ozone in the atmosphere. Time series of ozone spanning years or even decades are important to detect changes in ozone which are coupled to climate change, and to monitor and understand the depletion and expected recovery of stratospheric ozone. Stratospheric ozone measurements are also used for operational numerical weather prediction models to constrain the energy balance in the stratosphere allowing improved forecasts. Knowledge on the distribution of ozone in the upper troposphere is important to quantify its contribution to radiative forcing and thus improve the understanding of climate change. Ozone in the boundary layer has adverse health effects and is an important species in air quality. Although boundary layer ozone is difficult to detect using the ultraviolet backscattered spectra measured from space, the inferred information on the tropospheric abundance is relevant for air quality modelling.

The key to retrieve the vertical distribution of ozone in the atmosphere from ultraviolet (UV) backscattered sunlight is the sharp decrease in the ozone absorption cross-section between 265 and $330 \mathrm{~nm}$. Photons at the shortest wavelengths only penetrate the upper part of the atmosphere; therefore back-scattered short-wave photons contain information only of the upper layers of the atmosphere. Moving to longer wavelengths, deeper layers start to contribute to the back-scattered radiance. Beyond $300-310 \mathrm{~nm}$ (depending on the solar zenith angle) a sizeable fraction of the solar light reaches the surface. Combining the radiances over the whole wavelength range thus provides information of the ozone profile.

Published by Copernicus Publications on behalf of the European Geosciences Union. 
The Global Ozone Monitoring Experiment (GOME) was launched on the European Space Agency's second Earth Remote Sensing (ERS-2) satellite in April 1995 to measure backscattered ultraviolet (UV) and visible light at moderate spectral resolution $(0.2-0.4 \mathrm{~nm})$. To retrieve ozone profiles from its measurements in channels 1 and $2(240-404 \mathrm{~nm})$ several algorithms have been developed based on different techniques: optimal estimation (Barthia et al., 1996; Chance et al., 1997; Munro et al., 1998; Hoogen et al., 1999; Van der A et al., 2002; Liu et al., 2005), Philips-Tikhonov regularization (Hasekamp and Landgraf, 2001), and a neural network approach (Del Frate et al., 2002; Müller et al., 2003). An extensive intercomparison of these algorithms has been done by Meijer et al. (2006). Similar algorithms have also been applied to measurements from SBUV, SCIAMACHY, OMI and GOME-2.

At the Royal Netherlands Meteorological Institute (KNMI) the Ozone Profile Retrieval Algorithm (OPERA) (Van Oss and Spurr, 2002; Van der A et al., 2002) has been developed, based on the optimal estimation technique and able to ingest data from the satellite instruments GOME, GOME-2, and OMI. Since 2007, OPERA is used operationally for ozone profile retrievals from GOME-2 data in near real time. Using an older version of the OPERA algorithm, the quality of the retrievals from GOME data has been validated extensively by De Clercq et al. (2007) by comparing them with sonde, lidar, and microwave and by analyzing the averaging kernels. The validation shows that for 1996-1998 instrument degradation issues are least, and, consequently, retrievals are best. The stratospheric part of the profile typically agrees within $10 \%$ with the correlative data. The agreement in the tropospheric part depends mainly on the latitude of the ground-based station. At high latitudes agreements within $10 \%$ are found; in the tropical zone a bias of $35 \%$ and additional seasonal oscillations are found.

In this study, we evaluate the global performance of the algorithm by its convergence behaviour. Bad convergence statistics indicates where the algorithm has problems to retrieve an ozone profile. In this way we can isolate geographical problem areas such as South America (Sect. 4) and deserts (Sect. 5). Studying the convergence statistics also allows us to assess the influence of the input data (such as the ozone cross section and the ozone climatology) on the retrieval result, as will be shown in Sects. 6 and 8. Section 7 elaborates on the influence of the starting point of the iterations on the retrieval results. By implementing the algorithm adaptations and selecting better input data, the larger number of successful retrievals improves global coverage and increases average retrieval speed, facilitating the use of retrievals in near real time applications and the reprocessing of large datasets.

\section{Algorithm overview and retrieval configuration}

OPERA solves the inverse problem of retrieving the vertical ozone distribution from the measured radiance spectrum. In the forward step, it uses a radiative transfer model to calculate the spectrum from a model atmosphere including a first-guess ozone profile and estimates of cloud fraction and cloud height. The single scattering part of the radiation is computed with a fast single scattering model; the multiple scattering part is computed with the Linearized Discrete Ordinate Radiative Transfer model (LIDORTA) in four streams (Van Oss and Spurr, 2002), taking the sphericity of the atmosphere into account in the pseudo-spherical approximation. To limit calculation time, LIDORTA calculates scalar radiation fields. Polarization effects, which cannot be neglected (Hasekamp et al., 2002), are included afterwards by correcting with values from a look-up table that is created with the doubling-adding radiative transfer model which does include polarization (De Haan et al., 1987). In the inverse step, the difference between measured and simulated measurement is used to update the ozone profile and auxiliary parameters such as the effective surface albedo. The retrieval is ill-posed in the sense that many profiles give similar simulated spectra within given error bars. These profiles differ in their smallscale structures, which are not well constrained. By using the optimal estimation technique (Rodgers, 2000) an optimal solution is selected that combines information from the measurement with an a priori, climatological, ozone profile. Because of the non-linearity of the problem, an iteration scheme is needed to find the ozone distribution which minimizes the cost function. In this scheme the forward model and inverse step are repeated until certain convergence criteria are met on the solution (see below). To ensure a standardized set of starting points we will use the climatological profile also as the first guess in Sects. 4 to 6. In the comparison of the ozone climatologies in Sect. 8 the previously retrieved profile will be used as a first guess for the iteration, so that the climatology is only affecting the a priori data.

In this paper we test the performance of our algorithm (OPERA version 1.0.9) with GOME data, taking advantage of the extensive calibration effort put into the measurements of this satellite instrument (Van der A et al., 2002; Krijger et al., 2005). Retrieval of ozone profiles requires absolutely calibrated reflectivities which makes it very sensitive to the accuracy and precision of the reflectivity calibration (Van der A et al., 2002). Our results are based on the level $1 \mathrm{~b}$ product extracted with the GOME Data Processor, version 4.01 (Slijkhuis, 2006), which contains corrections for the degradation of the reflectance, the radiance offset, and the polarization sensitivity. We restrict ourselves to data from 1998, i.e. before degradation of the sun-normalised radiance sets in.

Table 1 summarizes the most important retrieval settings and input data. The ozone profile is fitted for 40 atmospheric layers distributed homogeneously over altitude from surface 
Table 1. Overview of the retrieval settings and input data.

\begin{tabular}{|c|c|}
\hline Retrieval algorithm & OPERA, version 1.0.9 \\
\hline Satellite data & $\begin{array}{l}\text { - GOME data (version GDP 4.01) from February and October, } 1998 \\
\text { - Pixel size } 960 \mathrm{~km} \text { (across track) × 100 km (along) } \\
\text { - Equatorial overpass time around 10:30 LST (local solar time) } \\
\text { - Reflectance and error calculated from solar irradiance, earth shine } \\
\text { radiance, and their errors }\end{array}$ \\
\hline Atmospheric model & $\begin{array}{l}\text { - } 40 \text { layers between } 41 \text { fixed pressure levels from } 1000 \text { to } 0.1 \mathrm{hPa} \text {, } \\
\text { equidistant in height } \\
\text { - ECMWF temperature profiles (ERA-40; see Uppala et al., 2005), } \\
\text { interpolated to time and location of retrieval } \\
\text { - No aerosols }\end{array}$ \\
\hline Cloud parameters & $\begin{array}{l}\text { Cloud fraction and cloud pressure retrieved from oxygen-A band by } \\
\text { FRESCO version } 4 \text {. Cloud albedo fixed at } 0.8 \text {. }\end{array}$ \\
\hline Forward model settings & $\begin{array}{l}\text { - } 40 \text { layers between } 41 \text { fixed pressure levels from } 1000 \text { to } 0.1 \mathrm{hPa} \\
\text { - Multiple scattering by LIDORTA (4 streams) } \\
\text { - Correction for inelastic rotational Raman scattering included }\end{array}$ \\
\hline Fit parameters, state vector & $\begin{array}{l}\text { - partial ozone columns for } 40 \text { atmospheric layers } \\
\text { - surface albedo (for cloud fraction }<20 \% \text { ) or cloud albedo (for cloud } \\
\text { fraction } \geq 20 \% \text { ) } \\
\text { - additional radiance offset in Band } 1 \text { a }\end{array}$ \\
\hline Fitting windows & $\begin{array}{l}\text { - Band 1a (265-307 } \mathrm{nm} \text { before } 8 \text { June } 1998 ; 265-283 \mathrm{~nm} \text { afterwards) } \\
\text { - Band 1b (308-313.5 } \mathrm{nm} \text { before } 8 \text { June } 1998 ; 282-313.5 \mathrm{~nm} \\
\text { afterwards). } 8 \text { pixels are co-added to match one Band 1a pixel } \\
\text { - Band } 2(315-330 \mathrm{~nm}) .8 \text { pixels are co-added to match one Band 1a } \\
\text { pixel }\end{array}$ \\
\hline $\begin{array}{l}\text { Ozone climatolog } \\
\text { (a priori and initial profile) }\end{array}$ & $\begin{array}{l}\text { Fortuin and Kelder }(1995,1998) \text { (reference setting) or } \\
\text { McPeters et al. (2007) or } \\
\text { TOMS version } 8 \text { (Frith et al., 2004) }\end{array}$ \\
\hline Ozone cross sections & $\begin{array}{l}\text { Bass Paur et al. (1985) (reference setting) or } \\
\text { Brion et al. (1993) }\end{array}$ \\
\hline Surface albedo & $\begin{array}{l}\text { Combined GOME/TOMS UV database for } \lambda=360 \mathrm{~nm} \text { based on } \\
\text { Herman et al. (1997) and Koelemeijer et al. (2003) }\end{array}$ \\
\hline Maximum nr of iterations & 10 \\
\hline
\end{tabular}

level to $0.1 \mathrm{hPa}$. Furthermore, OPERA fits either the surface albedo or the cloud albedo, depending on the cloud fraction. Validation studies show that retrieval quality is improved further when OPERA fits a radiometric offset between measurement and simulated reflectance in the Band 1a window. Cloud fraction and cloud pressure are derived from the oxygen-A band using the FRESCO algorithm (see Sect. 5).

\section{Convergence criteria and global retrieval performance}

Due to the non-linearity of the retrieval problem, the optimal estimation and its covariance are calculated numerically by using an iteration scheme which is based on the GaussNewton method (Rodgers, 2000). This requires a convenient criterion for stopping the iteration. Here, we break off the iteration when the difference between the error-weighted lengths of two consecutive state vectors $\boldsymbol{S}_{x}^{-1 / 2}\left(\boldsymbol{x}_{i}-\boldsymbol{x}_{i+1}\right)$ is below a fixed threshold $\varepsilon n$ :

$$
\left(\boldsymbol{x}_{i}-\boldsymbol{x}_{i+1}\right)^{T} \mathbf{S}_{x}^{-1}\left(\boldsymbol{x}_{i}-\boldsymbol{x}_{i+1}\right)<\varepsilon n
$$




\section{cumulative convergence}

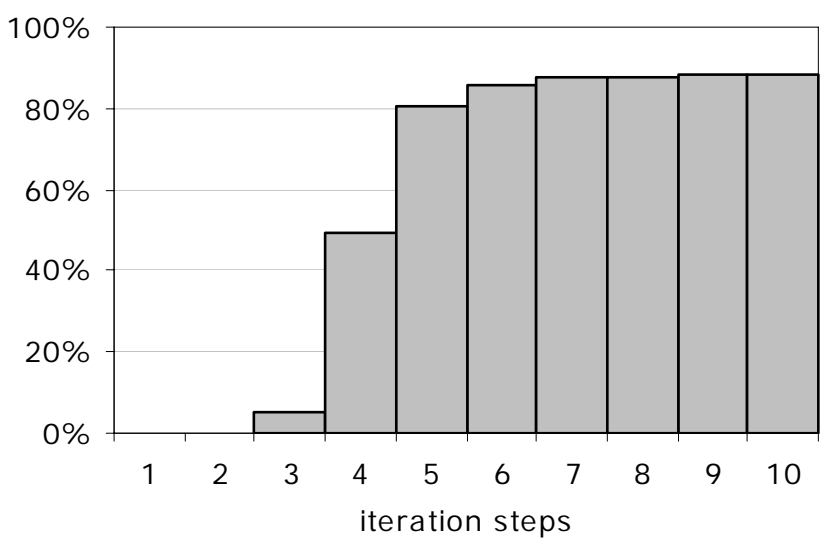

Fig. 1. Retrieval statistics for February 1998 with the settings of Table $1.11 .4 \%$ of the retrievals do not converge after 10 iteration steps.

in which $\mathbf{S}_{x}$ indicates the covariance matrix of state vector $\boldsymbol{x}_{i}$, and $n$ is the dimension of the "state space", the vector space spanned by the fit parameters (here, $n=42$ ). Throughout this study we will use $\varepsilon=0.02$. A stricter convergence criterion (e.g. taking $\varepsilon=0.01$ ) will slightly increase the mean iteration steps needed to reach convergence, but does not change the retrieval results significantly.

To investigate the algorithm behaviour for the full range of atmospheric and observational conditions, we use the algorithm with the default settings of Table 1 on a reference dataset of all retrievals in February 1998 ( 69000 retrievals in orbit number 14557 to 14957 , excluding narrow swaths). On average, 5.11 iteration steps were needed for convergence; $10.7 \%$ of the retrievals did not converge within 10 steps. As can be seen from the convergence statistics in Fig. 1, it is reasonable to break off the iteration after 10 steps when convergence criteria are still not met, since these retrievals apparently never converge.

We construct global monthly average fields of various parameters by projecting all GOME footprints on a grid of $1^{\circ} \times 1^{\circ}$. Figure $2 \mathrm{a}$ maps the mean number of iteration steps per grid cell, while Fig. $2 \mathrm{~b}$ shows the mean fraction of notconverged retrievals; a fraction of 1 indicates that for this grid cell all retrievals did not converge. In this way, different problem areas are uncovered. Apparently, the algorithm suffers from retrieval problems in distinct areas such as South America and deserts (e.g. Sahara and West Australia). The band-like structure over the Pacific, roughly from Ecuador to Papua New Guinea, appears to correspond with the position of the intertropical convergence zone (ITCZ) for this month.

The degrees of freedom for signal (DFS) is another useful measure to investigate the overall performance of the algorithm. Qualitatively, the DFS indicates how much information has been inferred from the measurements. If $n$ is (a) Mean number of iterations

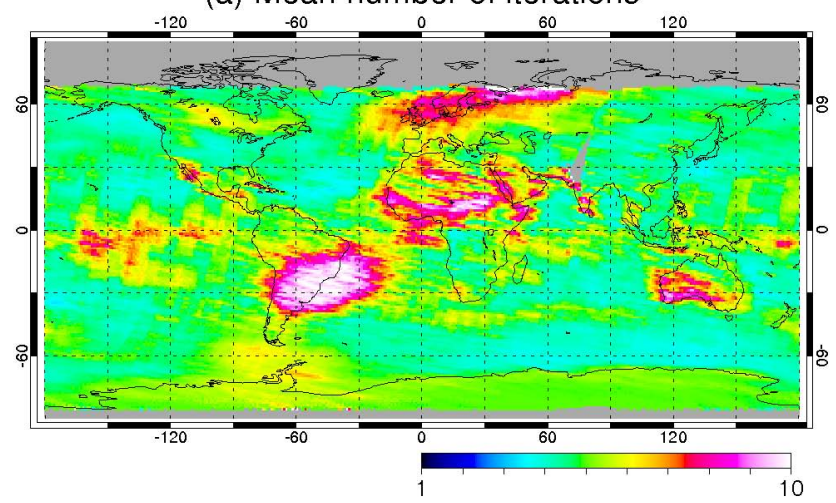

(b) Fraction of not converged retrievals

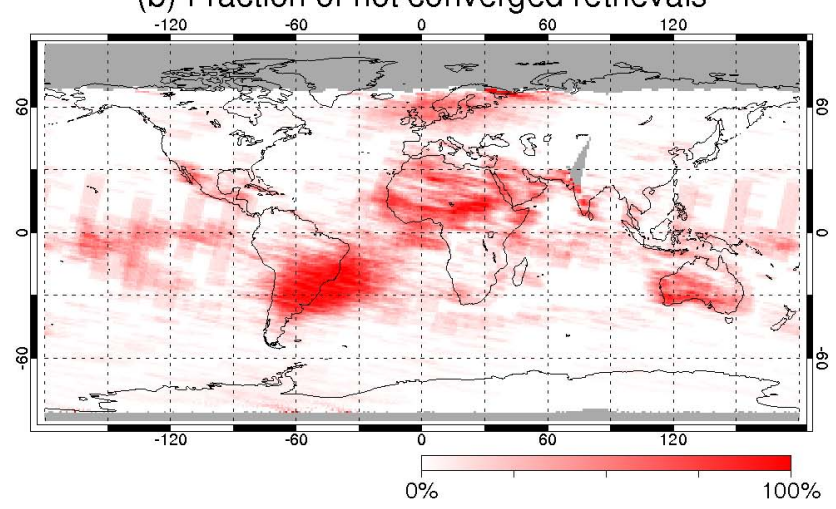

Fig. 2. (a) Mean number of iteration steps for all retrievals of February 1998. Non-converging retrievals are broken off after 10 iteration steps. (b) Fraction of not converged retrievals. Note the distinct areas of non-convergence.

the dimension of the state space, we have DFS $=n$ if the measurements completely determine the state vector, and DFS $=0$ if there is no information at all in the measurement, and the retrieval is completely determined by the a priori information. Typically, the DFS for the ozone profile fit parameters retrieved by OPERA for GOME measurements varies between 4 and 7 , governed by the a priori errors, the measurements errors and the sensitivity of the radiation to the profile. The latter varies mainly with the solar zenith angle, the cloud fraction and the surface albedo.

When non-convergence is caused by the quality of the measurements, the forward model, or its parameters, we will test the goodness of fit with the reduced chi-square. Here we will use the definition:

$\chi_{\text {red }}^{2}=\frac{1}{N} \sum_{i=1}^{N}\left(\frac{y_{i}-f_{i}(a, x)}{\sigma_{i}}\right)^{2}$

which gives the mean squared residue between observed reflectances $y_{i}$ and the corresponding forward model simulations $f_{i}$ at given ozone profile $x$ and model parameters $a$, normalized by reflectance error $\sigma_{i}$. The reflectance error is calculated from the relative errors in solar irradiance and 

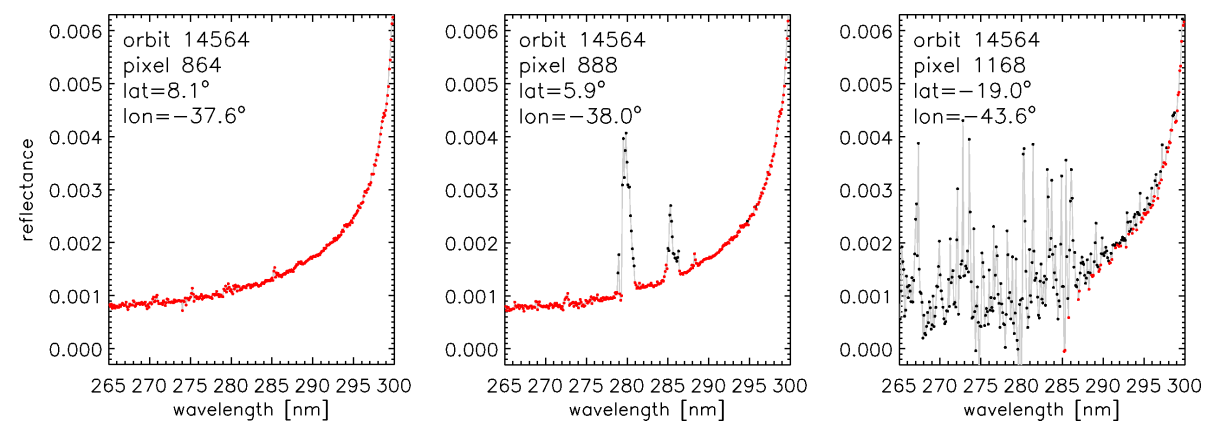

Fig. 3. Reflectance measurements in Band 1a for a typical measurement outside the SAA (left), on the edge of the SAA (middle), and in the centre (right). Measurements which pass the filter are indicated by the red dots. Spikes and noisy parts of the measurements are blocked by the filter.

earth shine radiance, both taken from the level $1 \mathrm{~b}$ product. If $\chi_{\text {red }}^{2} \approx 1$, the forward model fits well in the sense that the spectral residues show the spreading of measurement error. $\chi_{\text {red }}^{2}>1$ indicates systematic biases in the forward model (due to an unrealistic model or poor model parameters), or measurement errors which are larger than assumed.

\section{South Atlantic anomaly}

The area of non-convergence over South America in Fig. 2b corresponds with the location of the South Atlantic Anomaly (SAA). This is the region where the sunsynchronous satellite orbit (typically at $800 \mathrm{~km}$ altitude) intersects the inner Van Allen radiation belt. The high energetic particles (mainly protons and electrons) trapped inside this belt interact with the instrument, causing non-Gaussian noise and spikes in the measurements. Due to the weak signal level at short wavelengths, especially radiance measurements in Band 1a are affected by the SAA (see Fig. 3). The distorted spectra can not be simulated by the radiative transfer model (RTM), and causes convergence problems for the algorithm.

In order to avoid this type of non-convergence, an SAA filter was implemented. Basically, it disqualifies all measurements from the Band-1a fit which are affected by the impact of high energetic particles. This is done by considering the reflectance $R_{\text {ref }}$ at a certain wavelength $\lambda_{0}$ as a reference which is used to evaluate the validity of the neighbouring reflectance at the shorter wavelength side $R\left(\lambda_{i-1}\right)$. This measurement is considered a statistical outlier and disqualified if its value is higher than $R_{\text {ref }}$ plus $n$ times the reflectance error $\sigma$ :

$R\left(\lambda_{i-1}\right)>R_{\text {ref }}+n \sigma\left(\lambda_{i-1}\right)$

If not, $R\left(\lambda_{i-1}\right)$ is taken as a new reference value to evaluate the next measurement. Note that we only test an upper boundary condition; testing for a lower boundary condition is not as straightforward due to the decreasing reflectance values towards shorter wavelengths.
Figure 4a shows the retrieval results for February 1998, using the SAA-filter with parameters $\lambda_{0}=290 \mathrm{~nm}$ and $n=3$. By comparing with Fig. 2a, one can see that the SAA filter works well. For the region enclosing the SAA (here taken between $5^{\circ} \mathrm{S}-40^{\circ} \mathrm{S}$ latitude and $5^{\circ} \mathrm{W}-75^{\circ} \mathrm{W}$ longitude), the mean number of iteration steps is reduced from 7.51 to 6.88 , mainly caused by a drop in non-convergence from 52.6\% to $40.7 \%$. Globally, non-convergence drops from $10.7 \%$ to $9.9 \%$ for this month.

Filtering the measurements improves the goodness of fit of the forward model in the SAA region considerably: the reduced chi-square for converged retrievals drops from 52 to 6.5. Outside the SAA region the converged retrievals fit with $\chi_{\text {red }}^{2}=1.3$.

The effectiveness and selectivity of the filter can be seen in Fig. 4b, which shows the mean number of spectral measurements used for the retrieval. Although the filter criteria are applied to all observations, the filter is mainly active in the SAA. Outside the SAA all measurements are used for retrieval; deep within the SAA the measurements become so noisy that almost all measurements in Band 1a are discarded: the total number of used measurements drops from 587 to 370 . This causes the DFS to decrease, as can be seen in Fig. 4c.

\section{Low cloud fractions at deserts}

Since clouds in the field-of-view strongly affect the measured reflectance, they need to be included in the radiative simulation of the atmosphere. The convergence problems above deserts, as revealed by Fig. 2, can be related to the used cloud parameters. OPERA retrieves its cloud parameters by its in-built FRESCO algorithm, version 4 (Koelemeijer et al., 2001) in which clouds are represented by a Lambertian reflector described by an effective cloud fraction and a cloud pressure. The effective cloud pressure $P_{\mathrm{c}}$ and the effective cloud fraction $f_{\mathrm{c}}$ are derived from the reflectivities in the oxygen-A band (758-766 nm), based on the principle that clouds screen the oxygen below the cloud. In the continuum 
(a) Mean number of iterations

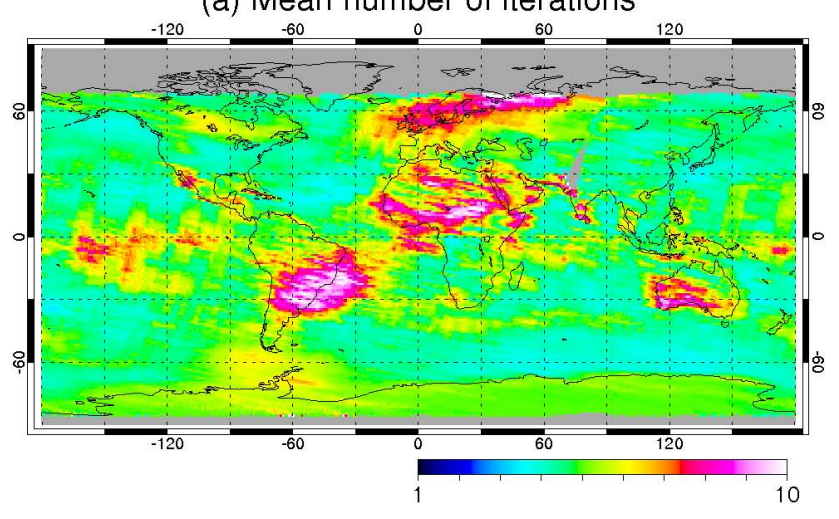

(b) Mean number of used measurements

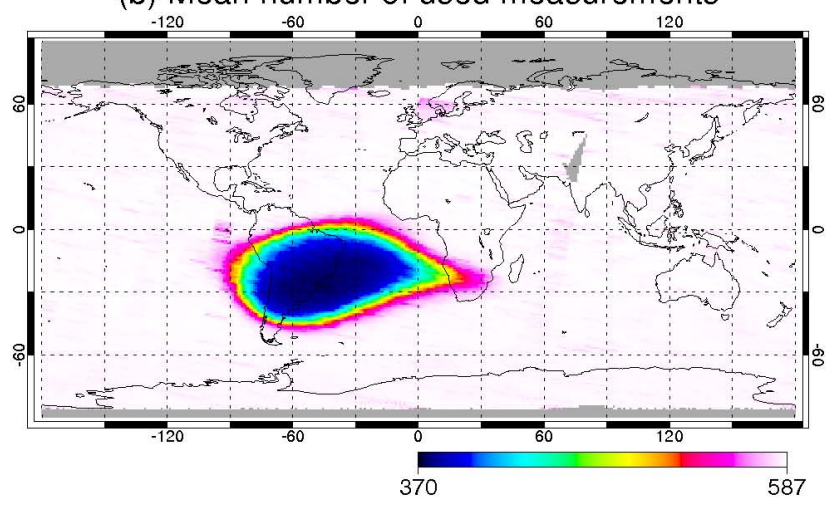

(c) Mean degrees of freedom for signal

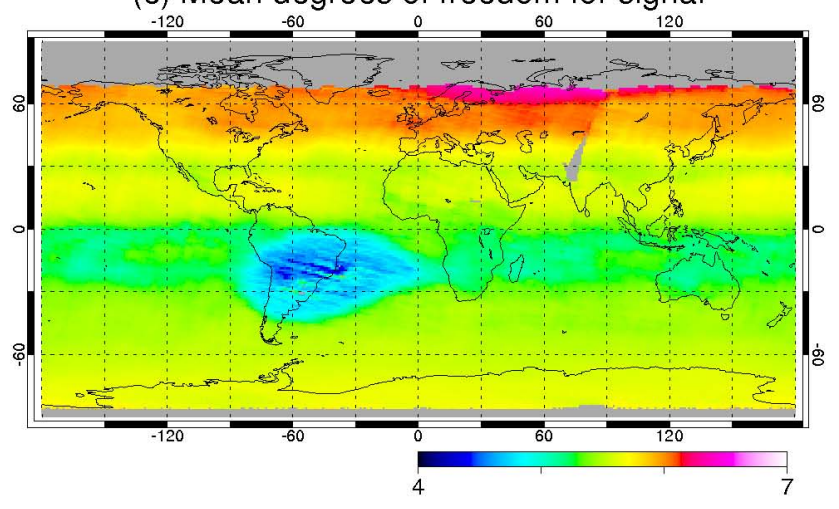

Fig. 4. Retrieval results for February 1998 with the SAA-filter applied. (a) Mean iteration steps. (b) Mean number of spectral measurements: only measurements in the SAA are affected by the filter. (c) The reduced number of measurements, however, results in a decrease of degrees of freedom for signal.

the reflectivity depends mainly on the cloud fraction, the cloud albedo (here assumed to be 0.8 ), and the surface albedo (taken from a monthly global minimum-reflectivity database; Fournier et al., 2006). The depth of the absorption band, however, depends also on the cloud pressure.

There are several other cloud parameter retrieval methods, such as using the (much weaker) $\mathrm{O}_{2}-\mathrm{O}_{2}$ absorption band at $477 \mathrm{~nm}$ (Acarreta et al., 2004). This is used for retrievals from e.g. the OMI instrument, where measurements at the oxygen-A band are not available. Van Diedenhoven et al. (2007) use the oxygen-A band with additional ultraviolet measurements between $350-390 \mathrm{~nm}$ to get extra information on cloud fraction and cloud optical thickness. By neglecting the opacity of clouds multiple scattering of photons in and below the clouds are not taking into account which introduces an extra retrieval error (see Liu et al., 2004). However, the small computational cost of the FRESCO algorithm compared to a more complex algorithm favours its application in OPERA.

The cloud parameters are used by the RTM, which performs two calculations: one cloud-free $\left(R_{\text {clear }}\right)$ and one fully clouded $\left(R_{\text {cloud }}\right)$ with clouds at pressure level $P_{\mathrm{c}}$. The reflectance for the partially cloudy scene is computed from $R=f_{\mathrm{c}} R_{\text {cloud }}+\left(1-f_{\mathrm{c}}\right) R_{\text {clear }}$ for each wavelength.

Depending on the cloud fraction, either surface or cloud albedo is included in the state vector. For $f_{\mathrm{c}} \geq 0.2$, backscattered radiation is dominated by the bright clouds: OPERA takes the surface albedo from a database and will fit the cloud albedo to find radiance closure at the top of the atmosphere. For $f_{\mathrm{c}}<0.2$ backscattered radiation from the surface becomes dominant, and OPERA will fit the surface albedo and sets the cloud albedo at 0.8 .

The majority of convergence problems over deserts is caused by a surface albedo which is fitted to negative values. FRESCO tends to overestimate small cloud fractions (see Fournier et al., 2006), because its minimum-reflectivity surface albedo database is not sufficiently decontaminated from the presence of absorbing desert dust aerosols and is therefore too low. The overestimated cloud fraction results in a simulated spectrum in which radiances are too high. In order to match the measured spectrum, the inverse step will lower the surface albedo. Because the initial surface albedo is small (typically 0.05 in the UV spectrum) and negative values are not allowed, there is not enough flexibility to compensate for the difference in radiance: the algorithm will not converge.

To prevent this problem, the following workaround has been implemented: if FRESCO retrieves $f_{\mathrm{c}}<0.2$ and in one of the consecutive iterations the surface albedo is fitted below zero, then $f_{\mathrm{c}}$ is set to 0 and the retrieval process is restarted. By doing so, the presence of clouds will be compensated by adjustments in the surface reflectance.

Although restarting to clear sky conditions takes at least one RTM-inversion cycle more, overall computation time is gained by avoiding non-convergence. Compared with Fig. 4a, Fig. 5a shows the improvement of retrieval results above deserts; global non-convergence statistics drop from $9.9 \%$ to $5.7 \%$. The selectivity of this workaround is shown in Fig. 5b by mapping for each location the fraction of retrievals to which it has been applied. As can be easily seen, it applies mainly to desert areas, especially Sahara and Australia, but also other sparsely clouded areas such as Mexico, India, and Namibia. 
(a) Mean number of iterations

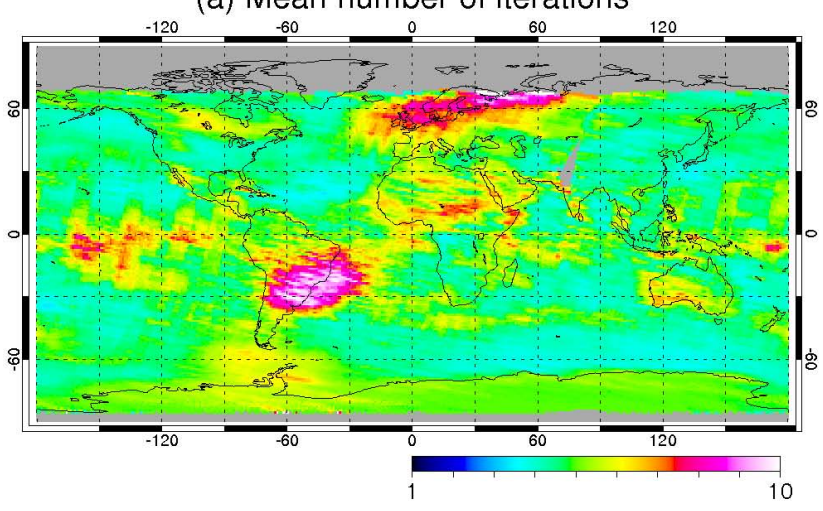

(b) Fraction applied desert-workaround

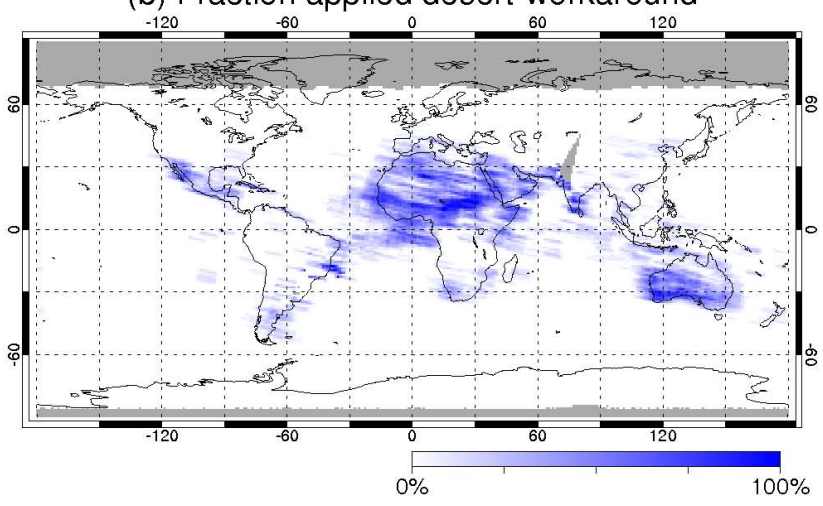

(c) GOME AOD at $500 \mathrm{~nm}$

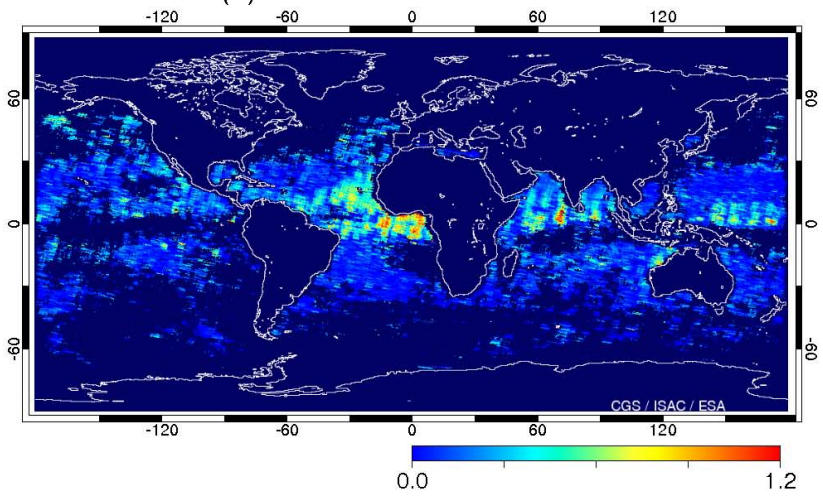

Fig. 5. Retrieval results for February 1998 with the desert workaround. (a) shows the improvement of retrieval results above deserts when compared with Fig. 4a; (b) shows the selectivity of the workaround by mapping for each grid cell the fraction of retrievals to which it has been applied. The convergence problem due to the dust outbreak flowing out from West Africa towards South America is also solved; as a comparison (c) shows the mean aerosol optical depth (AOD) at $500 \mathrm{~nm}$ for the same month (taken from http://www.temis.nl).

The presence of absorbing aerosols, which are not included in the atmospheric model, cause similar radiance closure problems at the top of the atmosphere. The proposed workaround also solves these convergence problems, as can be seen from the dust outbreak event in February 1998 flowing out from West Africa towards South America (Fig. 5c). The dust cloud absorbs radiation in UV, lowering the reflectance measured in this regime. At the same time, FRESCO attributes the increased reflectance around $750 \mathrm{~nm}$ due to the presence of the dust cloud over a dark ocean to an increased effective cloud fraction. These two effects will force OPERA to retrieve the surface albedo below zero, which can be avoided by assuming a cloud-free model atmosphere.

To investigate the impact of the error which is introduced by neglecting a small cloud fraction, we select a representative not-converging desert pixel, the centre of its footprint $900 \mathrm{~km}$ west from Lake Chad, with cloud parameters $f_{\mathrm{c}}=0.105$ and $P_{\mathrm{c}}=824 \mathrm{hPa}$ according to FRESCO. We perform a set of retrievals for this pixel with $P_{\mathrm{c}}$ fixed at $824 \mathrm{hPa}$ and $f_{\mathrm{c}}$ ranging from 0 to 0.2 . Figure $6 \mathrm{a}$ shows the dependence of the retrieved ozone column and the surface albedo on the cloud fraction: overestimation of the real cloud fraction is compensated by a darker surface and more absorbing ozone. For $f_{\mathrm{c}}>0.07$, the retrieved surface albedo becomes negative. Assuming a realistic surface albedo of! 0.05 for our pixel we estimate the true cloud fraction to be $f_{\mathrm{c}}=0.025$. In Fig. $6 \mathrm{~b}$ all retrievals are plotted; absolute deviations from the reference retrieval at $f_{\mathrm{c}}=0.025$ are showed in Fig. $5 \mathrm{c}$. By switching to a cloud fraction of 0 , the retrieved surface albedo increases to unrealistic high values ( 0.08 in our example). The retrieved total ozone column, however, decreases with less than $0.2 \%$. This decrease is caused by a decrease in partial ozone column of the lower model layers up to $17 \mathrm{~km}$; above the ozone bulk the profile does not change significantly. The goodness of fit of the forward model is not affected by this workaround, and remains $\chi_{\text {red }}^{2}=1.3$.

\section{Ozone cross-sections}

Another important quantity that determines the accuracy of the radiative transfer calculation is the ozone absorption cross-section at vacuum. In OPERA, cross-section values are calculated from a lookup table, which is parameterized by wavelength and temperature. Errors in the used crosssections can change the total retrieved ozone and the vertical distribution of this ozone significantly, as shown by Liu et al. (2007). Wrong cross-sections introduce an additional forward model error which influences the convergence statistics of the algorithm.

Here, we compare cross-sections from Bass-Paur (abbreviated BP) (Bass and Paur, 1985; Paur and Bass, 1985) and Brion (abbreviated BR) (Brion et al., 1993; Daumont et al., 1992; Malicet et al., 1995). For both cross-sections the wavelengths have been converted to vacuum wavelengths (see e.g. Orphal and Chance, 2003); temperature dependence is described by a second order polynomial fit. BP compares with $\mathrm{BR}$ to within $\sim 1 \%$ for wavelengths between $289-307 \mathrm{~nm}$ and temperatures between $209-278 \mathrm{~K}$. 
(a)

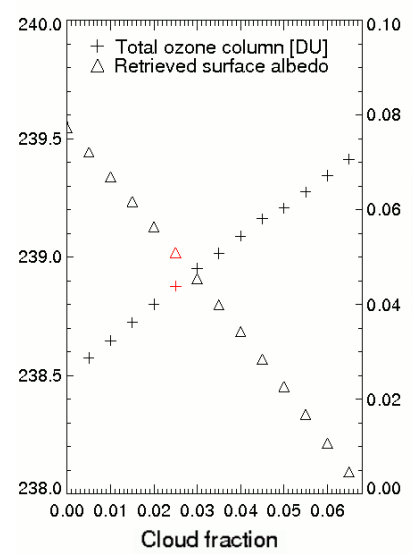

(b)

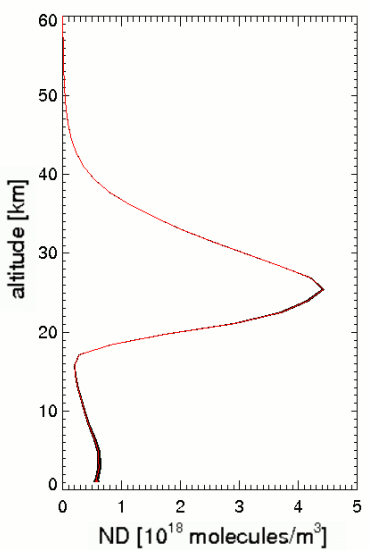

(c)

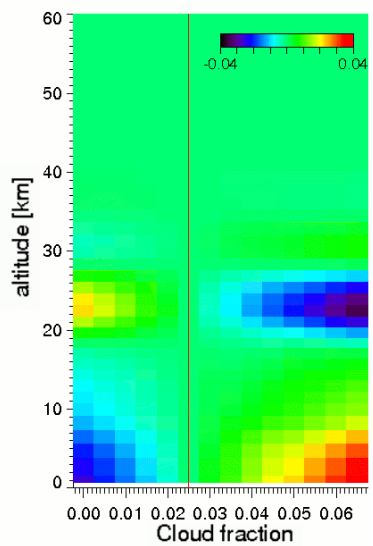

Fig. 6. (a) Dependence of retrieved surface albedo and total ozone column on the cloud fraction. In red, the retrieval corresponding to a surface albedo of 0.05, which is taken as a reference. (b) All retrieved ozone profiles. Small differences occur mainly in the lower part of the ozone bulk and in the troposphere. (c) shows the absolute deviation of number densities in $10^{18}$ molecules $/ \mathrm{m}^{3}$ for each atmospheric layer with respect to the reference profile at $f_{\mathrm{c}}=0.025$.

For $326-337 \mathrm{~nm}$ however, the mean BP cross-sections are higher by $1-2 \%$ than BR (Liu et al., 2007).

Switching from BP to BR ozone cross-sections improves the convergence statistics of the retrieval algorithm considerably: for February 1998 the non-convergence drops from $5.7 \%$ to $4.5 \%$ (compare Fig. 5a with Fig. 8a), while the mean number of iteration steps reduces slightly from 4.97 to 4.96 .

The improved convergence is the result of a better spectral fit of the forward model. The reduced chi-square drops from 1.3 to 1.2 .

Due to the lower values of the BR cross-sections, the algorithm compensates for the loss of absorbed radiance by increasing ozone in its model atmosphere. The mean retrieved total ozone column in February 1998 therefore increases from $289.8 \mathrm{DU}$ to $292.1 \mathrm{DU}$ (considering only retrievals which converge for both cross-sections), which is in accordance with the findings of Liu et al. (2007). For the same orbital data, the GOME total ozone column algorithm TOGOMI (Valks et al., 2004) retrieves an average column of 292.6 DU. Compared with BP, BR cross sections cause the average profile to increase $14 \mathrm{DU}$ in the $1000-100 \mathrm{hPa}$ range and to decrease $12 \mathrm{DU}$ in the $100-20 \mathrm{hPa}$ range.

\section{First guess}

As stated in Sect. 2, the iteration scheme of the algorithm needs a convenient starting point. So far, we used the climatological profile as a starting point for each retrieval, which ensures that the change in convergence behaviour of the successive experiments can be fully attributed to the algorithm adaptations. When processing complete satellite orbits, an common alternative strategy is to use the previous retrieval as a first guess, which - given the smooth gradients of the ozone field - provides a starting point close to the final retrieval. When no previous retrieval is available, due to nonconvergence or at the start of the orbit, OPERA will take its first guess from climatology.

In general, the number of iteration steps will be influenced by the distance in state space from the first guess to the true ozone profile. If the first guess is taken too far away, the algorithm can even fail to converge. To study the sensitivity of the convergence statistics on the first guesses we retrieved ozone profiles for February 1998 with both sets of starting points. This showed that the exact location of the first guess in state space hardly influences the convergence success: for both sets the non-convergence is $4.5 \%$. Even in the ozone anomaly of February 1998 above Northern Europe, where the true ozone column drops $60 \mathrm{DU}$ below to the climatological value, the first guess has a negligible influence on the convergence success. Also the shape and size of the retrieved profiles is the same. The partial ozone columns differ within $2 \%$ for the lower tropospheric layers, within $0.4 \%$ for the layers containing the ozone bulk, and even less for higher atmospheric layers. The real advantage of using the previous retrieval as a first guess can be found in the reduction of iteration steps, as shown in Fig. 7. The mean number of iterations steps for all retrievals in this month drops from 4.96 to 3.98 . In the ozone anomaly above Northern Europe the reduction in iteration steps is largest, dropping from 8 to 5 .

In very strong ozone anomalies which are not adequately described by the climatology (such as the ozone hole of October 1998), the true state can deviate too far away from the climatological value for the latter to serve as a first guess. The retrieval will not converge. Instead, by using the previous retrieval as a first guess the starting point is kept close to the true state. The ozone anomaly can be scanned deeper along the satellite orbit, up to the point where the first 
(a) First guess from climatology

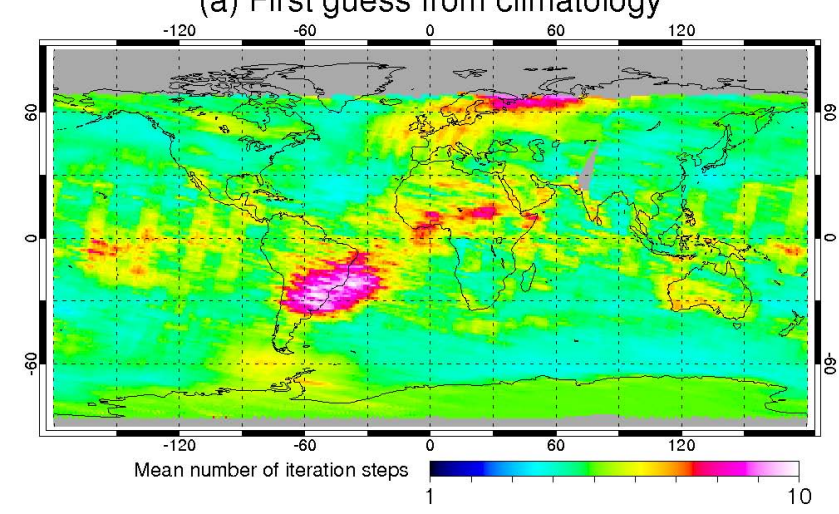

(b) First guess from previous retrieval

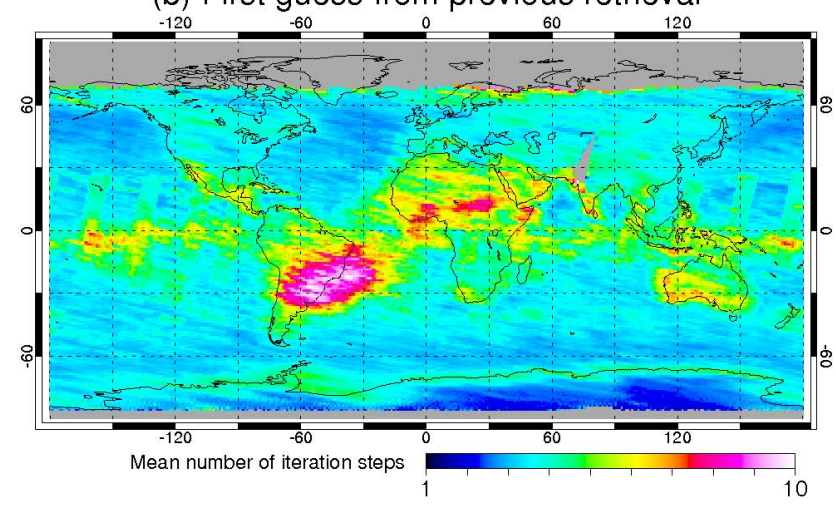

Fig. 7. Influence of first guess on number of iteration steps for February 1998: (a) mean number of iterations when taking the climatological profile as starting point; (b) mean number of iterations when the previous retrieval is used as starting point.

non-convergence occurs. Hereafter, the algorithm is forced to restart from climatology, resulting in non-convergence, until the anomaly resolves.

\section{Ozone climatologies}

In OPERA, the main use of the ozone climatology is to select an ozone profile at the latitude and time of retrieval which serves as a priori information for the optimal estimation. The retrieval benefits from an accurate a priori in altitude regions where the measurement is less sensitive to the presence of ozone since the retrieval tends to the a priori in that case. Convergence problems may arise when the a priori is not representative (either in shape, total ozone column value, or error) for the actual ozone distribution. To study the effect of the ozone climatology on the retrieval behaviour, we test three different ozone climatologies.

\subsection{Fortuin and Kelder}

The Fortuin and Kelder (FK) climatology (see Fortuin and Kelder, 1998) is based on measurements of 30 ozone sonde stations between 1980-1991, covering the appearance of the ozone hole period but excluding the Pinatubo eruption. It describes the monthly mean ozone volume mixing ration for 17 zonal bands, ranging from $80^{\circ} \mathrm{S}$ to $80^{\circ} \mathrm{N}$, at 19 pressure levels. The sonde measurements (from surface up to $10 \mathrm{hPa}$ ) are extended with the SBUV-SBUV/2 climatology (described in Randel and $\mathrm{Wu}, 1995)$ from $30-0.3 \mathrm{hPa}$. The standard deviation used here is the natural variability of ozone at each zonal band and at each pressure level for a certain month (Fortuin, 1996). For FK this is given up to $10 \mathrm{hPa}$; for higher atmospheric layers, OPERA extrapolates the error towards 0 at the top level. These standard deviations $\sigma_{i}$ for layer $i$ determine the diagonal elements of the a priori covariance matrix $\mathbf{S}_{\mathrm{a}}$. To allow for cross-correlations, off-diagonal elements are calculated using

$\left[\mathbf{S}_{\mathrm{a}}\right]_{i j}=\exp \left(-\frac{\left|\log P_{i}-\log P_{j}\right|}{d}\right) \sigma_{i} \sigma_{j}$

in which $d$ is the ozone profile correlation length per pressure decade, here taken 0.5.

\subsection{McPeters, Labow, and Logan}

The climatology by McPeters, Labow, and Logan (MLL) (see McPeters et al., 2007) is also based on sonde measurements (1998-2002) for the troposphere, but is merged with SAGE II measurements (1999-2002) for the higher atmosphere. MLS data (1991-1999) is used at high latitudes where SAGE data is not available. MLL describes the monthly mean ozone mixing ratio and its standard deviation for 18 latitude intervals of $10^{\circ}$ on 61 altitude levels $(0-$ $60 \mathrm{~km}$ ). For most months and heights, the variability of the climatology is smaller than in FK. As for FK, OPERA constructs the covariance matrix with a correlation length of 0.5 .

\subsection{TOMS version 8}

The TOMS version 8 ozone climatology (TOMS) (Bhartia and Wellemeyer, 2002) describes the monthly partial columns for 11 atmospheric layers for 18 zonal bands. In addition, it includes the total ozone column as an extra parameter to select the most appropriate profile when the total column is known.

To make a fast estimation of the total ozone column in OPERA, we implemented the Temperature Independent Differential Absorption Spectroscopy (TIDAS) algorithm by Zehner (2002). The principle of TIDAS is to use the difference of reflectance $\Delta R$ at two wavelengths $\lambda_{1}$ and $\lambda_{2}$. By selecting $\lambda_{1}=325.944 \mathrm{~nm}$ and $\lambda_{2}=326.746 \mathrm{~nm}$ for the GOME instrument, a compromise is made in which broadband spectral features can be neglected and $\Delta R$ is relatively insensitive to the temperature dependence of the ozone cross section, the influence of the Ring effect, and interfering trace gas species such as $\mathrm{NO}_{2}, \mathrm{ClO}_{2}, \mathrm{SO}_{2}$ and $\mathrm{BrO} . \Delta R$ becomes proportional 
Table 2. TOMS climatology variability for 11 layers and 5 latitude ranges.

\begin{tabular}{rrrrrr}
\hline & $90^{\circ} \mathrm{S}-60^{\circ} \mathrm{S}$ & $60^{\circ} \mathrm{S}-30^{\circ} \mathrm{S}$ & $30^{\circ} \mathrm{S}-30^{\circ} \mathrm{N}$ & $30^{\circ} \mathrm{N}-60^{\circ} \mathrm{N}$ & $60^{\circ} \mathrm{N}-90^{\circ} \mathrm{N}$ \\
\hline $1013-506 \mathrm{hPa}$ & $17.2 \%$ & $22.0 \%$ & $42.1 \%$ & $15.6 \%$ & $12.4 \%$ \\
$506-253 \mathrm{hPa}$ & $20.6 \%$ & $21.9 \%$ & $37.0 \%$ & $18.8 \%$ & $24.3 \%$ \\
$253-127 \mathrm{hPa}$ & $22.9 \%$ & $30.8 \%$ & $37.9 \%$ & $27.4 \%$ & $18.5 \%$ \\
$127-63.3 \mathrm{hPa}$ & $18.8 \%$ & $14.4 \%$ & $25.3 \%$ & $18.8 \%$ & $14.6 \%$ \\
$63.3-31.7 \mathrm{hPa}$ & $12.9 \%$ & $8.8 \%$ & $13.6 \%$ & $8.8 \%$ & $9.1 \%$ \\
$31.7-5.8 \mathrm{hPa}$ & $11.2 \%$ & $10.2 \%$ & $9.3 \%$ & $10.1 \%$ & $14.3 \%$ \\
$15.8-7.9 \mathrm{hPa}$ & $14.4 \%$ & $19.5 \%$ & $13.0 \%$ & $11.7 \%$ & $15.1 \%$ \\
$7.9-4.0 \mathrm{hPa}$ & $15.0 \%$ & $15.0 \%$ & $15.0 \%$ & $15.0 \%$ & $15.0 \%$ \\
$4.0-2.0 \mathrm{hPa}$ & $15.0 \%$ & $15.0 \%$ & $15.0 \%$ & $15.0 \%$ & $15.0 \%$ \\
$2.0-1.0 \mathrm{hPa}$ & $15.0 \%$ & $15.0 \%$ & $15.0 \%$ & $15.0 \%$ & $15.0 \%$ \\
$1.0-0.0 \mathrm{hPa}$ & $15.0 \%$ & $15.0 \%$ & $15.0 \%$ & $15.0 \%$ & $15.0 \%$ \\
\hline
\end{tabular}

to the ozone slant column and with help of a geometric air mass factor the total column can be estimated.

Comparisons of the TIDAS estimates with the vertically integrated column values retrieved by OPERA show an agreement within $8 \%$ for the latitude range of $-60^{\circ}$ to $+60^{\circ}$. For higher latitudes, the difference can increase to $11 \%$, but the TIDAS estimate is still appropriate for our purpose: selecting an a priori and initial profile from the climatology based on the estimated total column.

Unlike the other climatologies, TOMS does not contain error estimation. To determine its variability we compare the climatological profiles with all ECC sonde measurements done in 2000-2008 available at the World Ozone and Ultraviolet Radiation Data Centre (WOUDC). Most sonde data include the total ozone column, integrated from its measurements up to balloon burst and extrapolated with climatology, or taken from parallel ground-based or space-borne total column measurements. Based on this total column value we pick a profile from the TOMS climatology, which is interpolated to date, latitude, and total column value. From the difference between sonde and TOMS profile, the variability is determined for 5 latitude bands and 11 atmospheric layers (see Table 2). Due to balloon burst, not sufficiently statistical data is available above $8 \mathrm{hPa}$. Here a fixed $15 \%$ is taken, corresponding with the typical relative variability in and above the ozone bulk of the MLL climatology. The covariance matrix is constructed as in the FK and MLL climatology (Eq. 4).

The variability of TOMS shows that by including the total column as an extra parameter the base of the ozone bulk is better defined. For mid-latitudes the root mean square (RMS) error is $\sim 30 \%$ in the upper troposphere and lower stratosphere, while a priori profiles taken from FK or MLL typically show an RMS error over $70 \%$ for this region.

\subsection{Intercomparison}

We used the three climatologies for retrievals from GOME measurements of February and October 1998. For optimal performance, the algorithm is set to use the SAA filter, the low cloud fractions work-around, and the BR cross sections. For a fair intercomparison the previous retrieval result is used as first guess, so that the climatology is only affecting the a priori data.

A straightforward comparison between the climatologies is further complicated by the dependence of the climatological covariance on the DFS and the convergence criterion (Eq. 1). The optimal estimation uses the climatology to select the most probable profile from all profiles which have the same spectral signature within the given observation errors. Therefore, the retrieval quality based on a certain climatology can only be determined with an extensive validation study, which is beyond the scope of this paper. Instead, we concentrate on the convergence behaviour which displays the potential and limitations of the different climatologies.

Figure 8 shows the mean number of iteration steps for February and October 1998 ( $~ 78000$ retrievals in orbit number 18021 to 18464 ; excluding narrow swath) for the FK, MLL and TOMS. The convergence statistics and the mean DFS for February and October are summarized in Table 3. To give a representative value, the mean DFS is calculated for latitudes between $60^{\circ} \mathrm{S}$ and $60^{\circ} \mathrm{N}$ only, excluding the SAA.

For February, the results of the three climatologies are comparable. Best convergence is obtained with MLL (97.9\% converged retrievals, compared to $95.4 \%$ with FK), but at the cost of a lower DFS (5.25, compared to 5.56 with FK). The high convergence rate is facilitated by the small variability of the climatology, which forces the retrieval towards the a priori. Because less weight is put to the measurements, MLL shows also better convergence in the SAA. The weaker regularization by TOMS takes an intermediate position with $96.3 \%$ converged retrievals at a DFS of 5.44.

In October, the retrieval results are dominated by the presence of the ozone hole, which is at its maximum at the first weeks of this month. For both FK and MLL the monthly averaged climatology overestimates the real ozone column too much, causing the retrieval to take more iteration steps 
Table 3. Convergence statistics and mean DFS for different climatologies.

\begin{tabular}{lcccccccc}
\hline \multirow{2}{*}{ climatology } & \multicolumn{3}{c}{ February 1998 } & & \multicolumn{3}{c}{ October 1998 } \\
\cline { 2 - 3 } \cline { 7 - 8 } & $\begin{array}{c}\text { Not } \\
\text { converged }\end{array}$ & $\begin{array}{c}\text { Nr of iter. } \\
\text { steps }\end{array}$ & $\begin{array}{c}\text { Mean } \\
\text { DFS }\end{array}$ & & $\begin{array}{c}\text { Not } \\
\text { converged }\end{array}$ & $\begin{array}{c}\text { Nr of iter. } \\
\text { steps }\end{array}$ & $\begin{array}{c}\text { Mean } \\
\text { DFS }\end{array}$ \\
\hline FK & $4.6 \%$ & 3.98 & 5.56 & & $7.5 \%$ & 4.12 & 5.18 \\
MLL & $2.2 \%$ & 3.79 & 5.25 & & $6.7 \%$ & 4.07 & 4.76 \\
TOMS & $3.7 \%$ & 3.93 & 5.44 & & $2.0 \%$ & 3.76 & 5.14 \\
\hline
\end{tabular}
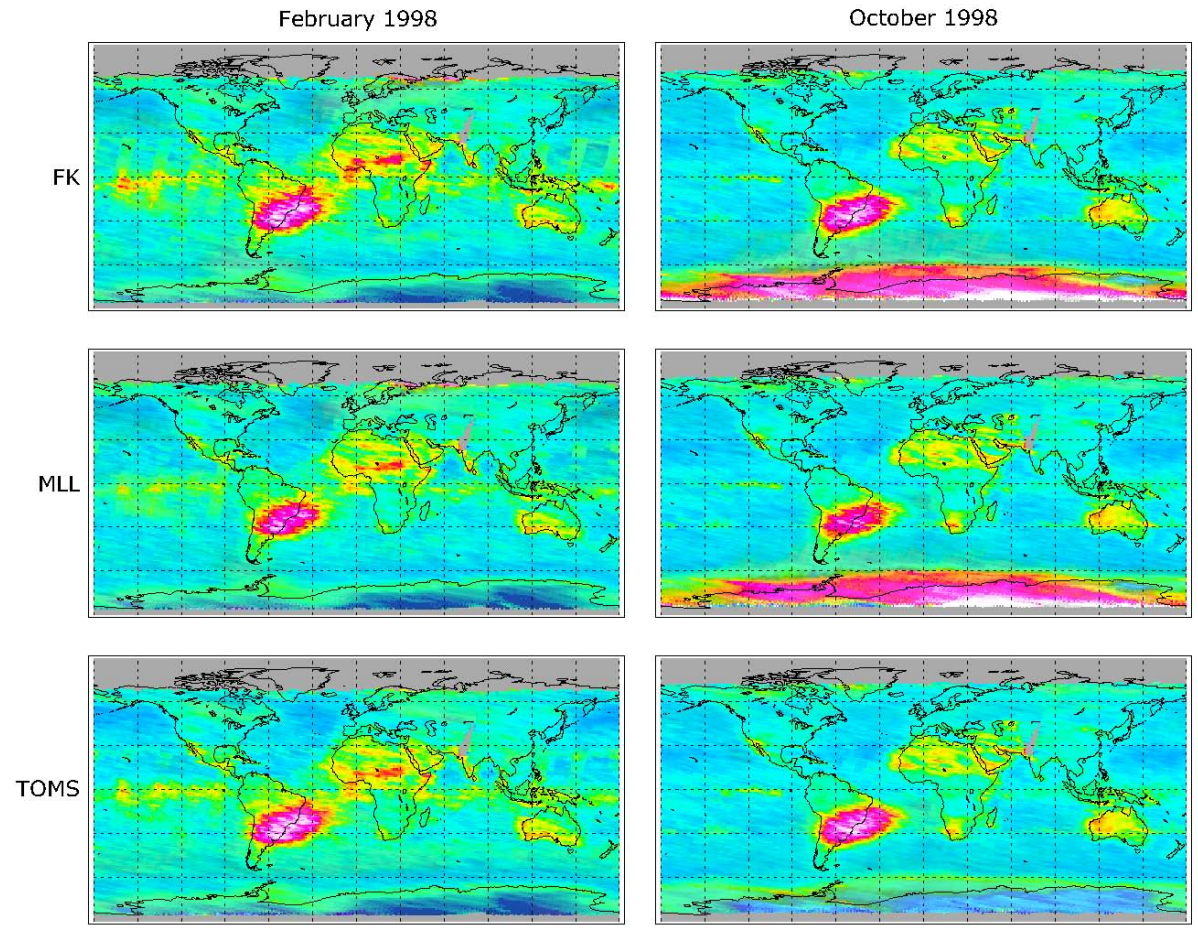

1

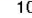

Fig. 8. Mean number of iterations for February 1998 (left panels) and October 1998 (right panels). In the rows the used ozone climatologies: FK, MLL and TOMS at a fixed relative error of $20 \%$.

to reach convergence, or not to converge at all. Because the TOMS climatology uses an a priori profile based on an estimated total ozone column, it offers a more accurate profile in these anomalous situations. South of $60^{\circ} \mathrm{S}$, only $2 \%$ of the TOMS retrievals do not converge, opposed to $44 \%$ for FK and $41 \%$ for MLL. The DFS for FK and TOMS is comparable at 5.18 and 5.14, respectively. Again, the DFS for MLL is notably smaller (4.76).

Also visible in Fig. 8 are the convergence problems around the equator related to the ITCZ (most notably in February 1998). The powerful convection in the ITCZ gives rise to a strong gradient in ozone concentrations between the bulk of the ozone and the very small concentrations in the troposphere. Here, the retrieval typically tends towards negative values for tropospheric atmospheric layers. This is not solved by any of the climatologies.

\section{Discussion and conclusion}

Studying the convergence behaviour of the ozone profile retrieval algorithm is a powerful diagnostic tool to test its overall performance. By mapping the non-convergence and number of iteration steps geographically for February and October 1998, we see how the algorithm behaves globally. Slow convergence or non-convergence can be the result of a variety of causes: measurement calibration issues or biases (e.g. in the SAA); bad forward model parameters (e.g. prescribed cloud parameters, ozone cross sections); an imperfect forward model (e.g. neglecting aerosols at dust storm events); bad a priori data (e.g. at ozone anomalies); first guess too far from the true state; and non-linearity issues (causing run-away or oscillating solutions). The presented results are based on GOME measurements, but the different causes of 
non-convergence are not unique for the GOME instrument; they will also show up (though not necessarily at the same strength) when the algorithm is applied to other spaceborne UV backscatter spectrometers.

Our reference experiment showed $10.7 \%$ non-convergence and an average of 5.11 iteration steps. By implementing an SAA filter, a workaround for low cloud fractions, better cross-sections and better starting points for the iteration, the mean number of iteration steps is brought down to 3.98, while the non-convergence drops to $4.6 \%$. As a consequence, more valid retrievals are done in less computational time.

The proposed SAA-filter filters out spiky measurements in the South Atlantic Anomaly region by excluding statistic outliers below $290 \mathrm{~nm}$. The filter is selective, affecting predominantly measurements within the SAA. The goodness of fit is improved considerably, resulting in better convergence statistics in this area (from $47 \%$ to 59\%), although at the cost of loss of DFS. Alternative, more elaborate SAA filter schemes can be implemented; note however that filtering too much of the unaffected measurements will cause unwanted information loss.

Problems with small cloud fractions from the FRESCO algorithm can be avoided by neglecting clouds and switching to clear sky retrieval. The hereby introduced errors are acceptable (a decrease of ozone in tropospheric layers cause the total ozone column to reduce $\sim 1 \%$ ). The workaround is selective and mainly affects desert areas like Sahara and Australia. It also fixes retrieval problems due to absorbing aerosols (such as desert dust outflow above oceans), which are not included in the atmospheric model. Switching to the new FRESCO+ cloud algorithm (Wang, 2006) in the OPERA software could also improve retrieval results above deserts. By taking Rayleigh scattering into account, the retrieved cloud fraction becomes 0.01 lower. Cloud levels also drop, depending on cloud fractions (e.g. $100 \mathrm{hPa}$ at $f_{\mathrm{c}}=0.2$ ). Both effects decrease the shielding of ozone by clouds in the model, favouring radiance closure at the top of atmosphere. In the future, the forward model could be further improved by including aerosols and a more realistic implementation of clouds, incorporating in-cloud and below-cloud multiple scattering, and angular dependent scattering.

Using Brion ozone cross-sections instead of Bass-Paur cross-sections strongly reduces the non-convergence of the algorithm. The improved convergence is the result of a better spectral fit of the forward model. Using BR cross-sections in the retrieval results reduces ozone in the lower part of the ozone bulk compensated by increased ozone the troposphere and lower stratosphere.

Two choices of a first guess profile in the iteration scheme are tested: the profile from the climatology or the profile of the previous retrieval. The choice of the first guess scarcely influences the convergence success. Also the shape and size of the retrieved profile is independent on its starting condition. The convergence speed, however, is improved when the first guess is closer to the truth. By taking the first guess from the previous retrieval instead from climatology the number of iteration steps is reduced by 1 on average.

The selection of ozone climatology in the optimal estimation importantly influences the retrieval results, such as convergence statistics, total column, profile shape, retrieval error, and DFS. We investigated this influence by comparing retrievals done with Fortuin and Kelder, McPeters and Labow, and the TOMS version 8 climatologies. Implementation of the TIDAS algorithm gives a quick estimate of the total column, accurate within $8 \%$ for the $-60^{\circ}$ to $60^{\circ}$ latitude range. The TOMS climatology has been extended with an error estimate by determining its variability against ozone sonde measurements from 2000 to 2008.

For February, the convergence results of the three climatologies are comparable. Retrievals with MLL show the highest convergence and lowest DFS, which suggest that the variability of MLL is too low to make optimal use of measurement information content in ozone profile retrievals. Both FK and MLL cause convergence problems at strong ozone anomalies which are not accurately enough described by the climatology. These problems are avoided with the TOMS climatology, which takes the total ozone column as an extra parameter to select a suitable a priori ozone profile. For studies of the ozone distribution in ozone anomalies (such as the ozone hole), the use of TOMS is therefore recommended.

The results might be further improved by using a climatology as introduced by Lamsal (2004), which also takes the total ozone as a dynamical proxy, but solving discontinuity issues over latitude, and including a realistic standard deviation.

Good convergence not necessarily implies good retrieval quality; the ozone profile retrievals based on a certain climatology should always be validated against independent measurements. But when selecting an ozone climatology for a specific application it is recommended to take also its convergence behaviour into account (combined with the degrees of freedom), considering available computational time, the desired use of measurement information content, and the ratio of successful retrievals in problem areas.

Acknowledgements. The authors wish to thank the European Space Agency for supplying the GOME level 1 data. To determine the variability of the TOMS climatology, ozone sonde measurements from 71 WOUDC sites were used. The authors acknowledge WOUDC for their effort in maintaining this WMO data centre. Edited by: Mark Weber

\section{References}

Acarreta, J. R., De Haan, J. F., and Stammes, P.: Cloud pressure retrieval using the $\mathrm{O}_{2}-\mathrm{O}_{2}$ absorption band at $477 \mathrm{~nm}$, J. Geophys. Res., 109, D05204, doi:10.1029/2003JD003915, 2001.

Bass, A. M. and Paur, R. J.: The ultraviolet cross-sections of ozone, I. The measurements, in: Atmospheric Ozone, edited by: Zerefos, C. S., Ghazi, A., and Reidel, D., Norwell, Mass., 606-610, 1985. 
Bhartia, P. K., McPeters, R. D., Mateer, C. L., Flynn, L. E., and Wellemeyer, C.: Algorithm for the estimation of vertical ozone profiles from the backscattered ultraviolet technique, J. Geophys. Res., 101, 18793-18806, 1996.

Bhartia, P. K. and Wellemeyer, C. G.: TOMS-V8 total ozone algorithm, OMI Algorithm Theoretical Basis Document, edited by: Barthia, P. K., Greenbelt, 2002, the climatology data can be downloaded at http://jwocky.gsfc.nasa.gov/version8/ version8update.html, last access: 19 July, 2010.

Brion, J., Chakir, A., Daumont, D., and Malicet, J.: High-resolution laboratory absorption cross section of $\mathrm{O}_{3}$, Temperature effect, Chem. Phys. Lett., 213(5-6), 610-612, 1993.

Brion, J., Chakir, A., Charbonnier, J., Daumont, D., Parisse, C., and Malicet, J.: Absorption spectra measurements for the ozone molecule in the 350-830 nm region, J. Atmos. Chem., 30, 291299, 1998.

Chance, K. V., Burrows, J. P., Perner, D., and Schneider, W.:, Satellite measurements of atmospheric ozone profiles, including tropospheric ozone, from ultraviolet/visible measurements in the nadir geometry: A potential method to retrieve tropospheric ozone, J. Quant. Spectrosc. Ra., 57(3), 467-476, 1997.

Daumont, M., Brion, J., Charbonnier, J., and Malicet, J.: Ozone UV spectroscopy I: Absorption cross-sections at room temperature, J. Atmos. Chem., 15, 145-155, 1992.

De Clercq, C., Lambert, J.-C., Granville, J., Gerard, P., Kaifel, A., Kaptur, J., Mijling, B., Tuinder, O., van Oss, R., and Zehner, C.: Geophysical information content and validation of ERS2 GOME ozone profile data records, IASB-BIRA Technical Note TN-IASB-GOME1-CHEOPS-01-1/B, Issue 1, Rev. B, 123 pp., 20 December, 2007.

De Haan, J. F., Bosma, P. B., and Hovenier, J. W.: The adding method for multiple scattering computations of polarized light, Astron. Astrophys., 183, 371-391, 1987.

Del Frate, F., Ortenzi, A., Casadio, S., and Zehner, C.: Application of neural algorithms for a real-time estimation of ozone profiles from GOME measurements, IEEE T. Geosci. Remote, 40, 22632270, 2002.

Dumitru, M. C., Hocke, K., Kämpfer, N., and Calisesi, Y.: Comparison and validation studies related to ground-base microwave observations of ozone in the stratosphere and mesosphere, J. Atmos. Sol.-Terr. Phy., 68(7), 745-756, 2006.

Fortuin, J. P. F.: An ozone climatology based on ozone sonde measurements, KNMI scientific report, WR 96-07, 1996.

Fortuin, J. P. F. and Kelder, H.: An ozone climatology based on ozone sonde and satellite measurements, J. Geophys. Res., 103(D24), 31709-31734, 1998.

Fournier, N., Stammes, P., de Graaf, M., van der A, R., Piters, A., Grzegorski, M., and Kokhanovsky, A.: Improving cloud information over deserts from SCIAMACHY Oxygen A-band measurements, Atmos. Chem. Phys., 6, 163-172, doi:10.5194/acp6-163-2006, 2006.

Hasekamp, O. P. and Landgraf, J.: Ozone profile retrieval from backscattered ultraviolet radiances: The inverse problem solved by regularization, J. Geophys. Res., 106, 8077-8088, 2001.

Hasekamp, O. P., Landgraf, J., and van Oss, R. F.: The need of polarization modelling for ozone profile retrieval from backscattered sunlight, J. Geophys. Res., 107, 1029, 2002.

Herman, J. R. and Celarier, E. A.: Earth surface reflectivity climatology at 340-380 nm from TOMS data, J. Geophys. Res.,
102(D23), 28003-28012, doi:10.1029/97JD02074, 1997.

Hoogen, R., Rozanov, V., and Burrows, J. P.: Ozone profiles from GOME satellite data: Algorithm description and first validation, J. Geophys. Res., 104, 8263-8280, 1999.

Krijger, J. M., Aben, I., and Landgraf, J.: CHEOPS-GOME: WP2.1: Study of Instrument Degradation, SRON-EOS/RP/05018, 2005.

Koelemeijer, R. B. A., Stammes, P., Hovenier, J. W., and de Haan, J. F.: A fast method for retrieval of cloud parameters using oxygen A band measurements from the Global Ozone Monitoring Experiment, J. Geophys. Res., 106, 3475-3490, 2001.

Koelemeijer, R. B. A., de Haanen, J. F., and Stammes, P.: A Database of spectral surface reflectivity in the range $335-772 \mathrm{~nm}$ derived from 5.5 years GOME observations, J. Geophys. Res., 108, 4070, doi:10.1029/2002JD002429, 2003.

Lamsal, L. N., Weber, M., Tellmann, S., and Burrows, J. P.: Ozone column classified climatology of ozone and temperature profiles based on ozonesonde and satellite data, J. Geophys. Res., 109, D20304, doi:10.1029/2004/JD004680, 2004.

Liu, X., Newchurch, M. J., Loughman, R., and Bhartia, P. K.: Errors resulting from assuming opaque Lambertian clouds in TOMS ozone retrieval, J. Quant. Spectrosc. Ra., 85, 337-365, 2004.

Liu, X., Chance, K., Sioris, C. E., Spurr, R. J. D., Kurosu, T. P., Martin, R. V., and Newchurch, M. J.: Ozone profile and tropospheric ozone retrievals from the Global Ozone Monitoring Experiment: Algorithm description and validation, J. Geophys. Res., 110, D20307, doi:10.1029/2005JD006240, 2005.

Liu, X., Chance, K., Sioris, C. E., and Kurosu, T. P.: Impact of using different ozone cross sections on ozone profile retrievals from Global Ozone Monitoring Experiment (GOME) ultraviolet measurements, Atmos. Chem. Phys., 7, 3571-3578, doi:10.5194/acp-7-3571-2007, 2007.

Malicet, C., Daumont, D., Charbonnier, J., Parisse, C., Chakir, A., and Brion, J.: Ozone UV spectroscopy, II. Absorption crosssections and temperature dependence, J. Atmos. Chem., 21, 263 273, 1995.

McPeters, R. D., Labow, G. J., and Logan, J. A.: Ozone climatological profiles for satellite retrieval algorithms, J. Geophys. Res., 112, D05308, doi:10.1029/2005JD006823, 2007.

Meijer, Y. J., Swart, D. P. J., Baier, F., Bhartia, P. K., Bodeker, G. E., Casadio, S., Chance, K., Del Frate, F., Erbertseder, T., Felder, M. D., Flynn, L. E., Godin-Beekmann, S., Hansen, G., Hasekamp, O. P., Kaifel, A., Kelder, H. M., Kerridge, B. J., Lambert, J.C., Landgraf, J., Latter, B., Liu, X., McDermid, I. S., Pachepsky, Y., Rozanov, V., Siddans, R., Tellmann, S., van der A, R. J., van Oss, R. F., Weber, M., and Zehner, C.: Evaluation of Global Ozone Monitoring Experiment (GOME) ozone profiles from nine different algorithms, J. Geophys. Res., 111, D21306, doi:10.1029/2005JD006778, 2006.

Müller, M. D., Kaifel, A. K., Weber, M., Tellmann, S., Burrows, J. P., and Loyola, D.: Ozone profile retrieval from Global Ozone Monitoring Experiment (GOME) data using a neural network approach (Neural Network Ozone Retrieval System (NNORSY)), J. Geophys. Res., 108(D16), 4497, doi:10.1029/2002JD002784, 2003.

Munro, R., Siddans, R., Reburn, W. J., and Kerridge, B. J. K.: Direct measurement of tropospheric ozone distributions from space, Nature, 392, 168-171, 1998. 
Orphal, J. and Chance, K.: Ultraviolet and visible absorption crosssections for HITRAN, J. Quant. Spectrosc. Ra., 82, 491-504, 2003.

Paur, R. J. and Bass, A. M.: The ultraviolet cross-sections of ozone, II. Results and temperature dependence, in: Atmospheric Ozone, edited by: Zerefos, C. S., Ghazi, A., and Reidel, D., Norwell, Mass., 606-610, 1985.

Randel, J. W. and Wu, F.: Climatology of stratospheric ozone based on SBUV and SBUV/2 data: 1978-1994, NCAR/TN-412+STR, 137 pp., 1995.

Rodgers, C. D.: Inverse methods for atmospheric sounding, World Scientific Publishing Pte Ltd, New York, 2000.

Slijkhuis, S.: CHEOPS-GOME Algorithm Theoretical Basis Document Level 0 to 1 processing update, DLR report CH-TN-DLRGO-0003, June, 2006.

Uppala, S. M., Kållberg, P. W., Simmons, A. J., Andrae, U., da Costa Bechtold, V., Fiorino, M., Gibson, J. K., Haseler, J., Hernandez, A., Kelly, G. A., Li, X., Onogi, K., Saarinen, S., Sokka, N., Allan, R. P., Andersson, E., Arpe, K., Balmaseda, M. A., Beljaars, A. C. M., van de Berg, L., Bidlot, J., Bormann, N., Caires, S., Chevallier, F., Dethof, A., Dragosavac, M., Fisher, M., Fuentes, M., Hagemann, S., Hólm, E., Hoskins, B. J., Isaksen, L., Janssen, P. A. E. M., Jenne, R., McNally, A. P., Mahfouf, J.-F., Morcrette, J.-J., Rayner, N. A., Saunders, R. W., Simon, P., Sterl, A., Trenberth, K. E., Untch, A., Vasiljevic, D., Viterbo, P., and Woollen, J.: The ERA-40 re-analysis, Q. J. Roy. Meteorol. Soc., 131, 2961-3012, doi:10.1256/qj.04.176, 2005.
Valks, P. J. M., de Haan, J. F., Veefkind, J. P., van Oss, R. F., and Balis, D. S.: TOGOMI: An improved total ozone retrieval algorithm for GOME, XX Quadrennial Ozone Symposium, 1/6/2004-8/6/2004, edited by: Zerefos, C. S., Athens, University of Athens, 129-130, 2004.

van $\operatorname{der}$ A, R. J., van Oss, R. F., Piters, A. J. M., Fortuin, J. P. F., Meijer, Y. J., and Kelder, H. M.: Ozone profile retrieval from recalibrated Global Ozone Monitoring Experiment data, J. Geophys. Res., 107(D15), 4239, doi:10.1029/2001JD000696, 2002.

van Diedenhoven, B., Hasekamp, O. P., and Landgraf, J.: Retrieval of cloud parameters from satellite-based eflectance measurements in the ultraviolet and the oxygen A-band, J. Geophys. Res., 112, D15208, doi:10.1029/2006JD008155, 2007.

van Oss, R. F. and de Haan, J. F.: Algorithm Theoretical Basis Document for OPERA, Issue 1.1, CHEOPS/KNMI/ATBD/001, 1720, 2004.

van Oss, R. F. and Spurr, R.J.D.: Fast and accurate 4 and 6 stream linearised discrete ordinate radiative transfer models for ozone profile remote sensing retrieval, J. Quant. Spectrosc. Ra., 75, 177-220, 2002.

Wang, P., Stammes, P., and Fournier, N.: Test and first validation of FRESCO+, Proceedings of SPIE volume 6362, Remote Sensing 2006, 11-16 September 2006, Stockholm, Sweden, 2006.

Zehner, C., Casadio, S., di Sarra, A., and Putz, E.: Temperature Independent Differential Absorption Spectroscopy (TIDAS) and Simplified Atmospheric Air Mass Factor (SAMF) Techniques for the Measurement of Total Ozone Content using GOME Data, Proceeding of ERS/ENVISAT Symposium, 16-20 October 2001, Goteborg, Sweden, 2001. 